\title{
INTERACTIVE INFOGRAPHICS AND NEWS VALUES
}

\section{Murray Dick}

This study is concerned with the news values and working practices that inform the creation of interactive infographics in UK online news. The author draws upon organisational theory in journalism studies, and considers how conventional journalistic news values compare with best practice as espoused in different literatures within this field. A series of open-ended, depth interviews with visual news journalists from the UK national media were undertaken, along with a short-term observation case study at a national online news publisher. Journalistic and organisational norms are found to shape the selection, production, and treatment of interactive graphics, and a degree of variation is found to exist amongst practioners as to definitions of quality in this field. Some news stories are considered to be better suited to rendering in interactive form than others. The availability of 'big data' does not drive decision making in itself, but some numbers are considered more newsworthy than others. Budgetary constraint drives practice and limits potential in this field. Risk aversion, embodied in various forms; from the use of templates, to a perceived need to avoid audience complaint, is found to dampen experimentation. Detailed audience research was found to inform the choice of methods used in data visualisation at one national news producer. This warrants further investigation as to how audiences engage with news interactives, and what the framing of news in certain (preferred) data visualisation formats means in terms of how news is understood.

KEYWORDS: interactivity, interactive graphics, interactives, infographics, news values, online journalism, digital journalism, visual journalism

\section{Introduction}

While interactive online journalism has been the subject of much analysis in contemporary communications studies (Boczkowski 2004; Bruns 2005; Deuze 2008), to date our understanding of the field of interactive visual journalism has been limited to output studies; including typological studies (Schroeder 2004; Quandt 2009), an audit of pre-existing materials in the context of newspaper workflow management routines (Giardina and Medina 2012) and a games-centric, end-usefocussed review (Bogost et al. 2010). But what of those individuals who create these innovative interactive story-telling devices? How they think and work is little understood in the literature.

The growing status of interactive graphics on our news and on the news profession more widely is evident within and beyond journalism practice. Today the Guardian has two interactive teams, one of which is concerned uniquely with its US audience. The BBC has a News Online Specials team, and The Times has a new Visual Journalism unit. Journalistic excellence in this field is officially recognised in the form of new professional awards such as The Data Journalism Awards (established in 2012 by The Global Editors' Network), and in new categories within existing industry awards, such as 'Digital innovation' in the Amnesty International 
Media Awards and 'The Digital Award' within The British Press Awards. There is a growing recognition of the potential for innovation, originality and excellence in the field.

The production of interactive visual journalism often involves bringing professionals from statistical, information design, and computing backgrounds into the newsroom. Do these professionals bring influences that in turn affect how interactive stories are selected, treated and published? Interactive news graphics inform the public sphere and the functioning of society just as traditional print and broadcast news formats do, so the professional norms at play are pertinent in any discussion of news values.

This exploratory study is concerned with establishing the routines, processes and relationships that shape the interactive news we consume. More specifically it aims to address a series of interconnected research questions:

What structure do interactives teams take, and what role and purpose do they serve in the modern newsroom?

How are news interactives ideas selected?

What creative processes are involved in the selection and treatment of news interactives?

What values inform the creation of news interactives?

Where does the audience factor within this creative process?

What distinguishes 'good' from 'bad' interactives?

This research is informed by three strands of scholarship; organisational studies of the newsroom, interactive online journalism studies, and a composite overview of best practice in interaction design and data visualisation (outlined in the Methodology section).

\section{Definitions}

The term 'interactives' is used throughout this study to describe news outputs in the sense set out by Nichani and Rajamanickam (2003): the purpose (or function) of these digital products is to facilitate explanation through interaction. The term is appended with 'news' simply to delineate the source of origination - 'news interactives' are created within the news industry, in a context of news production. It is acknowledged, however, that this is definition is coming under increasing pressure: for example, the 'Hacks and Hackers' social events, established in Massachusetts in 2009, and the Data Journalism Handbook (Gray et al. 2012) have problematized what it means to create interactive news, and what it means to be a journalist in this field.

\section{Organisational studies of the newsroom}

Journalists, it has long been argued, develop 'inferential frameworks' (Lang and Lang 1955), predicated on prevailing socio-cultural norms and developed through the course of experience in employment, which in turn informs the process of story selection, and the assembly and 'angle' of news. But as Schudson (1997) points out, this conception of the journalist tends to leave the information of which news is composed 'sociologically untouched'; as if it comes pre-prepared, rather than being subject to the process of negotiation. 
Some scholars have observed that conflict has a normalising influence on the production of news by journalists (Bantz, in Berkowitz 1997). Conflict and the competitive effectiveness of a specialism can set the status of some professionals in the newsroom. Tunstall (1971) showed that TV news and current affairs producers have significant autonomy, and that autonomy is granted as a result of a valued specialism.

Many early sociological studies of news work converge around the importance of the deadline as an organisational norm, and a determining factor in how news is 'manufactured', a theme which dominated the field studies of the 1970s and 80s; (Epstein 1973; Schlesinger 1987; Tunstall 1971; Golding and Elliott 1979). But where space is boundless, and where deadlines are not constrained within a fixed publication schedule, such issues cannot continue to be considered to direct our understanding of the inclusion and/or prioritisation of certain stories in news production (Franklin 1997).

Influenced by scholarship in the sociology of work, several studies by Wilson Lowrey (1999; 2002a; 2002b; 2003) explore how the news we receive is shaped by the conflicting norms held by competing sub-groups within the fluid setting of the news room. Lowrey found that the demands of organizational need are not the only determining factors at play in news production; professional norms and values are important too, particularly where professionals from a range of backgrounds come together to produce the news. Lowrey's approach allows us to move beyond the management structures and ideological norms that shape behaviour, to see the autonomy exerted by individuals over the news we consume. But this approach is premised on a binary conflict between 'word' and 'picture' people from a preconverged era. For the exemplar in the present study, we must consider the 'data person', and alternatively the statistician (or data journalist), the data visualisation expert (or graphic designer), and the computer programmer, all of whom may have their own pre-conceptions of what constitutes newsworthiness in data, and all of whom may exercise some degree of influence on the interactive graphics produced in today's news online. For this reason, in addition to establishing the role and functioning of interactive teams in the contemporary newsroom, the author also seeks to identify the extent to which 'interactive norms' exist within these professions, such as whether there is:

A common rationale to justify the creation of interactives;

Routinization of work processes (that may speak to organisational norms in this field)

Consistency in approaches to best practice in data visualisation (such as a common position on the 'chartjunk' debate in the literature), and;

Consistency in approaches to best practice in human-computer interaction (such as a common position on the significance of user-centredness, and the factoring of emotion into interaction design).

\section{The rise of interactive online journalism studies}

Interactive online journalism has its own field study literature, which in turn draws upon the organisational journalism studies literature of the past (Boczkowski 2004; Bruns 2005). However, interactive visual journalism has more often been researched from an 'outputs' perspective, which tells us little about the decisionmaking that goes into this field of news production. Schroder's (2004) survey of 
interactive infographics shows that the UK media lagged behind their European counterparts in this field, over the last decade. Similarly, Quandt (2008) pulled together the dominant themes in late 1990s literature on the formal and structural properties of news content online, to show that online media had an over-reliance on 'shovel ware' from print.

In the middle of the last decade, the rise of the network brought a new utopianism to journalism studies literature, bound up with the notion that "...the profession would have to articulate an equilibrium between its operationally closed working culture strictly relying on a ruling elite of 'experts', and a more collaborative, responsive, interactive or even dialogical journalistic culture" (Dueze 2003, 219). Supplanting the classic 'gatekeeping' role of the news journalist in the networked age, Bruns' theory of the 'gatewatcher' (which takes after Gans' 'multiperspectivality' [1979]) has at its heart a long-established US communications ideal: the marketplace of ideas. But this approach belies a significant reality: just because 'the former audience' now has access to (some of) the news source material journalists used to monopolise, does not mean that they have the time nor inclination to create or disseminate their own news.

A range of literature on the very general theme of interactivity in online news production has some bearing on the present study, but only at a tangent. These can broadly be classified as either functional studies (Kenney et al. 1999; Rosenberry 2005; Shultz 1999; Tankard and Ban 1998), concerned with how interactive elements in online news are presented; and perceived studies (Chung 2007; Larsson 2012) concerned with how interactivity is understood by the audience.

\section{Methodology}

This research employs two methodologies; a short-term observation case study, and a series of semi-structured, depth interviews. All subjects are visual journalists working in the UK news media, but they come from, alternatively; journalistic, graphical design, and programming and development professional backgrounds.

In total eight hours of observations were undertaken with the BBC News Online Specials Team over two separate days: Wednesday 15 August 2012 and Wednesday 22 August 2012. This team create interactive and non-interactive infographics that are published on the BBC News website. This team has editorial and budgetary autonomy within the news organisation, and take responsibility for management of their own workload. During observation, the author attended editorial and team meetings, and both observed and interacted informally with journalists, designers and programmers working across the team (involving ten staff in total).

Seven semi-structured, depth interviews were undertaken with six interactive journalists working across the UK national media. Two interviews were undertaken with Channel 4 News Online's Head of Infographics on Friday 27 July 2012, and Tuesday 16 October 2012, with further questions answered via email exchange between these dates. Two interviews were undertaken with the editorial lead of the BBC News Online Specials Team on Wednesday 15 August 2012 and on Wednesday 22 August 2012. A joint-interview with The Guardian's (now former) Head of Graphics, and a long-serving graphic and interactive designer was undertaken on Monday 23 July 2012. An interview was undertaken with former head of The Daily Telegraph's graphics team and current Director of the Society of 
Newspaper Design Region 15, on Thursday 30 August 2012. An interview with Head of Interactive at the Financial Times was undertaken on Friday 22 February 2013.

In total, these interviews comprised ten hours. Recordings were made, and notes taken during observations and interviews, and findings were summarised from all notes in around 12,000 words. The subjects chosen for this research were not selected at random - the field of interactive news graphics professionals in UK news is small, and the author was guided primarily by access.

Questions asked during observation and interviews covered many areas, including:

How do you decide what stories to cover?

What does the process of creating interactives involve?

How do you maintain the quality of your work?

Are some stories better suited to interactive graphics than others?

Do you work with some newsdesks or teams more than others?

Are some numbers more 'interesting' than others in terms of producing interactives?

Is there an ideal news subject/story type which particularly lends itself well to rendering in interactive graphics?

Do you have any assumptions about your audience which inform your interactives?

How to do you measure the success of your interactive graphics?

Questions were developed iteratively, and framed according to subjects' experience of terminology and process. Best practice in interaction design was derived from an international standard (ISO 2009), and from the literature, especially as regards the foregrounding of emotion in interactive design (Forlizzi and Battarbee 2004; Saffer, ed. 2010). Best practice in data visualisation was drawn from the works of Brinton (1914); Tufte (1983); Holmes (1984) and Tukey (1990) as well as a British Standard on the presentation of tables and graphs (BSI 1992). The debate over the merits of visual embellishment in data visualisation, or 'chartjunk' (Bateman et al. 2010) is revisited here, as is Tufte's 'Doctrine That Statistical Data Are Boring' in the newsroom. Journalistic norms are derived from work in print, broadcast and online journalism cultures; and are bound up with those conventional ideas of accuracy, fairness, detachment and objectivity long established in professional codes of conduct, and long critiqued in journalism and communications scholarship.

The weighting of responses is broadly proportionate to the range of participants, but reflects individual concerns. Thematic analysis was undertaken using a contextualist approach, with regards those themes found in the 'best practice' literature. This study takes a grounded, theory-building approach - it is acknowledged that the conclusions drawn here are not generalizable beyond the sample, though it is hoped that this research will inform future, more systematic studies.

\section{Findings: observational study}

The early morning editorial meeting for BBC News Online (held at 9:30AM) comprises members from each 'index' page, chaired by a central news editor. The meeting I observed started with a summary overview of the previous day's stories 
and audience statistics, then a general overview of the day's main stories. Each index page representative then explained their top two or three stories for the day. A home affairs story concerning Asil Nadir's court case was raised, a story for which the Specials team developed a (non-interactive) graphic:

http://www.bbc.co.uk/news/uk-19161940 (retrieved August 2013)

The Specials team representative talked through their two pieces of work for the day (the graphic above, and an interactive in preparation concerning youth unemployment). The meeting is declarative, descriptive and not exploratory or creative, and is expressly not about decision-making - this happens later via direct email or phonecall between interested parties, away from group dynamics.

Everyone listens, but there is no real show of reaction. Later John Walton (deputy head of the Specials team, who represents at this meeting) explains that the selection of stories and methods of coverage used are driven by resources, and by potential for impact. Producing interactives can be time-consuming and resourceintensive, so ideas need to be feasible and credible. The team usually require contribution from subject specialist journalists on large projects. The Specials team are more likely to accept the offer of work on a story (a commission) where that story is likely to rise up the index pages to UK or World pages (the dominant pages in BBC News Online).

Project teams are tripartite, comprising data journalists, designers and developers, in numbers reflecting the volume of work anticipated - data journalists are ultimately tasked with editorial decision-making. At any one time one designer will be allocated to working on short-turnover projects while another will concentrate on features.

John spends much of the late morning reading a government document on youth unemployment: Global Employment Trends for Youths. He also spends considerable time on the phone (around forty minutes) speaking to an expert in the newsroom about alternative sources for data on this topic. One of the designers is re-working a satellite view map of Syria, where the Golan Heights hadn't been displayed properly. It is thought the map had been rushed because the previous day had been busy (and the team under-staffed), and subsequently questions were raised about the choice of colours used and the use of geographic space, which didn't give a clear impression of borders. The team spend a significant amount of time testing their output, and comparing it with the output of competitors. Bella (Hurrel, editorial lead) shows me a graphic produced two days previously by an American competitor, concerning charitable giving. Its strengths and weaknesses as a story-telling device are discussed informally with colleagues, in person and via email.

In keeping with all other news teams, the Specials team are inclined to develop user generated content in their output - one such 'high-end' example is given: Rover Panorama, a 360 degree visualisation:

http://www.bbc.co.uk/news/science-environment-19296006

(retrieved August 2013)

In this instance the Specials team worked with non-BBC developer Andrew Bodrov, who (using images sourced directly from NASA), created a sophisticated montage of space exploration. The Specials team added data points, in order to 
render the collection interactively. Rights issues have forced the team into acts of creative ingenuity. One of their developers has created a bespoke Google Chrome browser extension which allows for quick conversion of raw data into maps, making this tool available to BBC journalists via their staff intranet. This was done through necessity, due to prohibitive rights issues concering use of digital map imagery, and to bring technical support for the system in-house.

The Specials' recently appointed acting head of development said his news values come from BBC audience values, around accessibility and diversity. He mentioned that one of their current projects had raised ethical dilemmas around the sourcing of data. He received a large amount of proprietary data from an organisation who in return wanted publicity around the issue of music piracy. The team were planning to create an interactive area-map of music piracy across the UK. He said they had to make difficult decisions about this, and be careful not to use the data in a way that may work to the commercial advantage of the source who provided the data. He sees journalists as 'customers' - he works in web development first and foremost. He explains that there is some editorial over-lap between project managers and data journalists; suggesting the rise in tensions caused by the increasing fusion of form and content in online journalism.

\section{Findings: interviews}

\section{Interviewee details}

A Channel 4 interactive news specialism has existed since 2010. Ciaran Hughes' career background is in newspaper graphics.

The BBC Specials team has existed since 2003. Today it comprises eight journalists, four developers and four designers. Bella Hurrel's background is in arts journalism.

The Guardian's interactive team was created in 2001. Paddy Allen was a founder member of the team, and his background is in newspaper graphics. Michael Robinson's background is in newspaper design.

Michael Agar's background is in infographic design across various national newspapers. He was formerly head of graphics at the Telegraph between 2008 and 2012.

The FT Interactives team has existed since 2005. Today it comprises 9 members, equally weighted between data journalists, developers and designers. Emily Cadman's background is jointly in magazine and news journalism.

\section{The status and function of interactives journalists within the newsroom}

All participants are involved in editorial decision-making at their respective organisations. Drawing comparison with colleagues who work in TV graphics, Ciaran explains that his work is far more involved editorially, in generating ideas and in treatments: "I differ from the TV guys, in graphics; I won't react to a script - I'm much more involved from the very start in editorial and not just in deciding what we do and how we do it do, but in suggesting subjects, I'm involved in visual journalism" (Hughes, Ciaran. Interview by author. Digital recording. London, July 27, 2012). In the past, when working in newspaper graphics Ciaran's work would often provide support to the story of the day. Personal politics influence roles - some duty editors are more sympathetic to graphics (and interactives) than others, often depending on 
their own journalistic background. This is true of the BBC too - Bella explains that the placing of interactives within stories can in turn lead to disputes across departments, driven by scarcity of resources. Bella prefers the Specials team to create self-contained interactives rather than visual accompaniments to other team's news stories, because this involves retaining full editorial control. This approach creates impact; it yields page impressions, social media 'shares', and various other data (including interaction data), that can be directly attributed to the team's work. This audit trail can in turn re-enforce the team's editorial integrity and independence.

Emily explains that over the past three years it has become easier for her to express the importance of the interactives team at the FT as more and more journalists have become interested in interactive graphics as a journalistic medium, and as technological advances have made it easier to do their job. Similarly, Paddy explained that he finds it easier to convey the team's significance to the Guardian's editors today (having moved from print graphics to interactives), but that this has been a slow process over a long period. Seven years ago it had been very difficult, he explains:

I used to have to rush around quoting all the time 'your story is $70 \% \ldots$ more likely to be read if it has a graphic next to it', and it was a desperate attempt to talk people into why you should have these things... and quite often they would come up with briefs that were spectacularly inappropriate, but because they were higher up the food chain than you, they would want it like that (Robinson, Michael and Paddy Allen. Interview by author. Digital Recording. London, July 23, 2012).

Michael Robinson feels the main aspect which has changed such attitudes is the process of bringing designers and art directors into newspapers, a process which has loosened sub-editors' control of the visual space in news. He explains that his job was originally created (in 2002) in order to address tensions between the 'word' and 'picture' professionals at the Guardian. Poor time restraint, poor briefs, and poor scope were all considered to undermine graphical and design potential. He feels that the interactives team have benefited from these past arguments and resolutions. Paddy says that a positive consequence of working online is the potential to sit down and get on with work:

The demands for the web are very different in that you have limitless room, so you haven't got Adverts who might come in and say 'you haven't got room for this anymore'. It is far more open, in that if any of us has a half-decent idea, they will say 'yeah you can go ahead with that', and you can start there and then, but the paper will say 'well that might be a good idea, if we have room' (Ibid).

This in turn is important in terms of building self-confidence within the team, and professional cache outside the team - in print there is an ambient threat that a day's work may be discarded on account of the arbitrary intervention of a news event.

The BBC Specials' long-term strategic aim is to move beyond providing content for different editorial units, towards provide journalists with their own tools (an approach driven jointly by increasing interest in news interactives, and by tightening budgets). Similarly, Michael Agar's experience at the Telegraph involved building applications for journalists. Doing so allowed his former team to concentrate on longer-term projects, while empowering their non-specialist peers. 


\section{Who decides what stories become news interactives?}

Commissioning in the BBC Specials team is approximately $40 \%$ internal (where a team member is commissioned to create infographics by the Specials editor) and 60\% external (where other teams and departments engage the Specials editor with work), though this is prone to vary: "Sometimes it's more of a conversation" (Hurrel, Bella. Interview by author. Digital recording. London, August 15, 2012). Data journalists will select a newsworthy topic, or a large dataset, or at planning or commissioning meetings ideas will be raised. The team do their own newsgathering, but they don't have the budget to undertake investigative work: "If you have a big data set there's no point in going fishing in it... because you can waste a lot of time" (Ibid). On major stories the team are guided by experts, both inhouse (in the form of correspondents and section editors), and externally by the Royal Statistical Society or the Office for National Statistics. At the FT there is a mixed approach to commissioning. Simple commissions that can be done in a day (such as timelines, or profile pictograms) are readily undertaken, but larger projects will only be started upon if they are likely to be carried on a main index page, or if the team stands to learn something from doing the project (which will, it is felt, in turn improve or streamline future coverage). Unlike the BBC Specials team, there is a propensity (and indeed a perceived necessity) to undertake 'fishing' exercises in large data sets, and so undertake original investigative work.

Paddy explains that the commissioning process at the Guardian is very open, and that some stories generate interesting commissioning situations. At the time of writing the political crisis in Syria was unfolding quickly, and commissioning has largely being driven by the live-blog of the story. Paddy had been working on a live interactive graphical map - updated day by day, and showing the changing state of conflict. This approach was in turn influenced by reporting decisions made during the Arab Spring the previous year, as Michael observed: "“if the coverage has worked in one part of the world on a certain aspect, then that is exactly what will kick off all the ideas for the next news event" (Robinson, interview, July 23, 2012).

\section{News values: what to cover and how?}

The values that inform Ciaran's approach to deciding what work to undertake, come from years of working in news rooms. The commissions he seeks (and accepts) are ultimately sanctioned and decided higher up the editorial chain, and his work (both interactive and non-interactive) is a product of this decision-making process. Similarly, Michael Agar's news values stem from his experiences of pitching ideas to news editors. His is a utilitarian approach: "I can't understand why people would spend time cleaning and processing data if there were no story in it" (Agar, Michael. Interview by author. Digital Recording. London, August 20, 2012). Bella also comes from a traditional journalism background that informs her news values, but she observes that the culture of developers and designers does have an effect on the team's collective approach. Editorial decision-making remains constant (structurally top-down) but non-journalists tend to question orthodoxies more: these professionals often have a different working culture and a different understanding of deadlines: "they question basic assumptions about the importance, and timing of coverage - they create a debate" (Hurrel, interview, August 15, 2012). 
What is the basic justification for an interactive?

Ciaran feels that interactives work well on news stories and topics that contain comparisons, and they can be particularly effective on stories concerning many parties and their interconnectedness. He gives an example of an animation he put together on the financial crisis at Rangers Football Club in May 2012 that was repurposed into a video narrated by chief correspondent Alex Thomson, and then republished on YouTube:

http://www.channel4.com/news/rangers-complex-connections-explained (retrieved August 2013)

Interactives take one of three forms at the BBC Specials team:

'Big data' stories, concerning stories buried in large data sets...non-statistical process visualisations that help the audience understand an issue ....and personalised information generators, such as calculators (Hurrel, interview, August 15, 2012).

Emily suggests that interactives that allow the user to explore something that affects them directly, or that encourage the exploration of complicated major topics are most important at FT.com. Alternatively, those stories which do not generally work so well as interactives are those "to go with a piece where there is a lot of reportage - a good, written piece based on interviews, anecdotes or interpretations" (Cadman, Emily. Interview by author. Digital Recording. London, February 22, 2013).

\section{Are some numbers more newsworthy than others?}

Ciaran thinks that some numbers are more interesting than others, and that some visualisations of information can work counter to conventional news values: "quite often when you visualise (data for a story), (the visualisation) goes against the story... a $2 \%$ increase or a $5 \%$ increase...you show it and it looks incremental" (Hughes, interview July 27, 2012). Sometimes the numbers don't look particularly newsworthy, but by plotting data over a longer timeframe, or by bring in another variable, a news story may emerge. Sometimes Ciaran works backwards (chronologically) from the numbers he is given, and finds stories to report on that are often political in nature (challenging the claims made by politicians). These are often published on the 'Fact Check' blog:

http://blogs.channel4.com/factcheck/

(retrieved August 2013).

Michael Agar said:

Most stories are designed to fit a headline anyway, so if the statistics are boring then you have no story, unless, you are hanging it on a story where a politician saying figures are amazing (when in fact nothing has changed), then that is the story" (Agar, interview August 20, 2012). 
Bella said that 'outliers' often make for good stories, as do stories which involve processes or personalisable information (such as school league tables). At the Guardian there are competing views. Michael Robinson is wary of walking into a semantic trap in regards to the newsworthiness (or otherwise) of certain numbers: "The method you are using in difference or comparison may be wrong, it isn't the numbers, if it is your treatment of them. You could say 'there is no graphic in that' but if it is relevant that it is flat, stability can be the issue. But it might be boring..." (Robinson, interview, July 23, 2012). Paddy argues that the outlier often makes things more newsworthy as "a crude rule of thumb" (lbid), but Michael interjects: "that can be naughty - who spent the most, who spent the least... but if you are looking at statistics, you should chop off the extremes, when it comes to representative data" (lbid). Taking a different approach to the other respondents, Emily explains that the FT's news values (and audience interest) is very much bound up in numbers which may appear 'boring' to some audiences; such as GDP figures that may change little, or that are rarely surprising, but that these are nonetheless the foundation for policy and political issues which affect everyone, and so are therefore crucial to the FT.com audience.

\section{'Good' infographics}

Bella says that the BBC Specials team are somewhere in the middle of the spectrum in terms of the 'chartjunk' debate: "we talk about it a lot - in terms of accessibility, feel, engagement we try to go for [David] McCandles, but it has to work - it has to be accurate... complaints would make it impossible [to experiment too freely]" (Hurrel, interview, August 15, 2012). Michael Robinson advocates Tufte's theories, but acknowledges he is "a bit boring... If you want a bible up there I would put his work above others, the others are more like wallpaper" (Robinson, interview, July 23, 2012).

Michael Agar is a fan of Tufte, but is more mindful of the work of Alberto Cairo, adding "I'd like to think you can back the academia up with a bit of fun" (Agar, interview, August 20, 2012). He believes emotion has an important function in news interactives, albeit in a pervasive way: "I think visually, we don't need to be as extreme with the emotion (as those writing the words) there still has to be an element of human interest there... but I can see where the conflict lies" (Agar, interview, August 20, 2012). Ciaran is influenced by Tufte, whom he describes as being "like an engineer - his work has a beauty in itself. Good design has an innate beauty, elegance" (Hughes, interview, July 27, 2012). Ciaran recognises the importance of emotion, but conceives of it as a first order component of the medium - he doesn't think there need be an impasse with objectivity (as is manifest, for example, in balance) in journalism:

If I'm telling you a story, the words I choose, the way I speak, the emphasis it's all a matter of emphasis, it's always there - in any communication it's always there. The thing about engaging - it's actually like David McCandles (Information is Beautiful). It doesn't matter, it might be worthless - but if it is beautiful you will look at it, and realise it's worthless. If it doesn't engage you, if you don't get instant satisfaction (which is very important) then you will never get to the second layer: 'what is this showing?' (Hughes, interview, July 27, 2012).

\section{'Bad' infographics}


Ciaran explaines that an inability to grasp the difference between an information graphic and an illustration has been, in his experience, the source of bad interactive and infographic ideas in the past. According to Bella, some general issues may lead to bad commissions, for example over-prescriptiveness on the part of other teams and journalists in the corporation (commissioning an interactive that will enhance a story to make it more successful, but not to explain or explore the story or data better). Similarly, she explains that journalists (and readers) like maps, but the geographical location of a story is not always central to its significance, and the use of satellite imagery in maps for visual impact isn't always the most appropriate representation. Maps are nonetheless used to add verity to stories, to give the audience a sense of rootedness in their own space and geography, to connect them with news events, even when this is not appropriate to the story being told.

Michael Agar says that he had engaged in some bad commissions in the past in order to serve a purpose in the newsroom. He recalled a story comparing the cost of bread in the 1940s and today - involving a series of pictorial slides. This commission, from a senior news editor, served the purpose of encouraging the print newsroom to make more use of infographics as a means of online-only story publishing. Emily has been asked to undertake 'bad' commissions at the FT, but they've never been published. Sometimes she has questioned whether some commissions represent the best use of her time.

\section{Newsroom relations}

Ciaran does not work particularly closely with any other teams in the newsroom, though in the past, and as a non-interactive visual journalist, he spent much time with business journalists. Bella explains that a number of subject areas are more naturally aligned with the BBC Specials team than others, as much due to established relationships between staff, as by sympathetic subject matter or source types (she lists Science, Technology, Home Affairs and Business as regular commissioners). Paddy says that the environmental journalists at the Guardian have been particularly good partners in the development of interactives, because many of their stories are inherently visual. Michael Robinson is mindful of administrative issues that can drive workloads too - he mentions that his graphics team used to do very little for the Features desk on the Guardian's G2 magazine, but since they started attending the same meetings, they have started working more closely together. At the FT, the interactives team work most with the Investigations Unit, and with Public Policy and World News desks (the latter require a lot of maps to explain geo-political and globalisation stories, and key members of this team are enthusiastic about multimedia in general).

\section{Interactive news style and audience}

Channel 4 News Online have a style guide that dictates text (titles, capitalisation etc.), and a colour guide (created by Ciaran). Ciaran is mindful that audience assumptions are imagined assumptions, and he is cynical about the value of using focus groups (and user testing). At the FT most interactives are user-tested on spouses and colleagues around the interactives team - but not on the public. 
Nevertheless, the audience (and not functions, or systems) are central to development there.

The BBC Specials team use templates for regular story-types. Because they must appeal to all sections of society, Bella explains they try to make their work as simple as possible without being patronisingly reductive. Focus groups (with members of the public), guerilla testing and even long-term ethnographic research has been undertaken to find out more about their audiences. They have found that a portion of the general public are intimidated by charts of all kinds, because they remind them of unhappy memories of studying mathematics at school. Equally, some audiences find circles more visually appealing (they are less tainted by experience, or feelings of confusion or inadequacy). At the BBC it is considered vital to incorporate audience research into their decision-making and processes. Page impressions, volume of clicks, and levels of interaction on pages containing their interactives are all measured and analysed: the Specials team have been able to iterate their work based on this data. Most of the findings are 'common sense', but they can inform selections and routines in practice. A general rule they've found is that in taking a prescriptive narrative approach, more readers are likely to complete all stages of the interactive - so this approach is often preferred to experimental interactive graphics. The choice of degree of interaction employed is driven by perceptions of audience, not by an idealist notion of interactivity. BBC online style is set out in a Global Experience Language (http://www.bbc.co.uk/gel retrieved July 2013).

The Guardian have a graphical style, a colour palate and interactive templates that are driven by functionality. They have five different timeline types for different scenarios. The Guardian undertakes a good deal of user research, but little of it is presented directly to the Interactives team: "Sometimes you are so immersed in a culture that you take it on board via osmosis... this is probably a very bad thing..." (Allen, interview, July 23, 2012). Michael counters that "the assumptions about fitting content to an audience can be a big mistake, the audience are merely using a medium" (Ibid). Focus groups have been used, and the team receive feedback directly from readers. They undertake paper prototyping and user design on major projects. Responding to reader comments is considered to be more useful than market research. Michael is worried that the availability of interaction data may change the way they do their work, for the worse - he is wary that the availability of this data may bend their values in selecting and treating stories for interactives in a more a populist direction.

The FT interactives team have a basic style guide and colour palate (to which, from time to time they negotiate additions). They also use various templates, and will on occasion give access to these templates to particular journalists (they will also informally train interested journalists in various skills). They measure performance in terms of conventional web analytics, but they do not as yet collect interaction data (albeit Emily would like to). Feedback comes directly from readers, and both formally via an editors' letter every Friday night, reviewing the best story from the entire week's operation, and informally from colleagues around the organisation. Given the highly-educated (and numerate) nature of the FT audience, Emily does not feel constrained by complexity when it comes to designing interactives.

\section{Analysis}


Those driving the creation of interactive graphics in our news "talk the talk" (Lowrey 2002a, 419) of professional journalism because many of them come from journalistic, rather than data, graphical or programming backgrounds. As such those conventional journalistic values concerning accuracy, fairness, detachment and objectivity dominate the way in which work is undertaken in this field, in the UK media. Professional values from other domains find voice, concerning attitudes to deadlines, and the questioning of conventions and reasoning around coverage or treatment of news stories. The notion of journalists as 'customers' is held by some development professionals within this field - which in turn poses further questions about the nature of interactives journalism, and its place in the newsroom. But for the most part, non-journalistic professional values are dampened by the culture of the newsroom, and the mix of positivist journalistic and organisational values.

Interactives journalists do not prioritise pleasing other journalists over the efficacy of their own work, and evidence of a "service-department" (Lowrey 2003, 138) mentality, as found in non-interactive graphic work, was not found here. Today's interactives professionals are becoming more self-confident, more creative, and less 'auxiliary' than their non-interactive predecessors in UK newsrooms. These journalists seldom compromise their professional integrity on account of what they perceive to be 'bad ideas', or the perceived innumeracy of others in the newsroom.

Where conventional journalistic norms do not dominate, organisational norms prevail. This is found most clearly where professional norms are not fixed. For example, not all interactive teams comply with best practice in terms of user-centred design. There is some variation in the perception of what constitutes 'good' interactive graphics, within the wider debate concerning 'chartjunk'. Most participants recognise the merit in Tufte's work and values, but it is also clear that the importance of visual impact in the sense set out by Tukey, represents a potential clash with Tuftian minimalism. Some practioners see themselves as working somewhere between the minimalism of Tufte and the experimentalism of David McCandles. Some numbers are considered more newsworthy than others - an approach that accords broadly with Tufte's positivist stance: "If the statistics are boring, then you've got the wrong numbers" (Tufte 1983, 80). Ultimately budgetary constraint casts a shadow over practice and potential in this field. The development and use of templates serves to de-specialise the specialist. Risk aversion, embodied in the fear of audience complaint, and in the use of detailed, prescriptive audience research, dampens experimentation.

But on the other hand, budgetary constraint also gifts interactives teams with a powerful bargaining mechanism within the editorial structures of the media organisations in which they practice, allowing them to challenge orthodoxies, and contribute to the news agenda. Today's interactives teams not only provide education and guidance, but produce bespoke software and provide ad hoc training for non-specialists to do their own work - their authority is based not just upon how they do their own work, but on how they can facilitate others to more effectively and efficiently do their work too.

There is no agreed framework amongst interactives practioners on what constitutes a justification for the production of a news story in interactive form, nor on what forms are appropriate in particular news story scenarios, though it is clear that the issue of quality (however conceived) is a driving factor in practice. The competing views and theories presented in the Findings here offer a very different perspective from those theories and typologies that are focussed on end-use (Bogost et al. 2010). 
The rise of the network can be said to account in part for the raised status of these professionals, and this new journalistic form. Some reach out to the audience as co-producers and involve them in design. On the other hand, audience behaviour is measured, and use is made of audience metrics towards informing future ideas for coverage. Clearly some interactives journalists are become gatewatchers, but others maintain a more traditional approach to their audience; basing creative judgements on 'gut' instinct (Schultz 2007), while responding to the audience primarily via the route of editorial feedback. For some the only influence from outside the newsroom comes from statistical and data visualisation experts, precluding all but a tiny number of audience members from participation in this field of news production. Equilibrium between the operationally closed newsroom and the 'former audience' in this field seems unrealistic in the near term.

Interactives are more suited to some news stories than to others, on account of narrative type and the dynamics involved. Interactives are not necessarily more suited to particular subjects or niches than others, but in practice they are more likely to emerge in some fields than others. This is due in part to the availability of 'newsworthy' data, and in part to newsroom dynamics. The resource-intensive nature of producing interactive graphics limits what stories may be selected for coverage, and 'important' stories are more likely to be selected for coverage. Only one of the organisations covered in this study (with a niche, rather than general audience) provide their interactives teams with the budget to investigative or delve deeply into large data sets. It would be wrong to presume, therefore, that the recent explosion in availability of data from government may lead to greater scrutiny within the conventional fourth estate. The rise of the network has brought 'big data' into the newsroom, but the availability of 'big data' is not a reason for investigation or coverage in itself. On the other hand, some numbers are considered more newsworthy than others amongst professionals in this field -so it may be that studies of news values (or story selection criteria) based upon normative lists (Galtung and Ruge 1965; Golding and Elliott 1979; Allern 2002) may require re-appraisal in light of this.

Some of the most popular applications of interactivity in this field, such as personalisable calculators, represent an up-to-date form of 'news you can use', and some conventional graphical formats (such as charts) are avoided because they 'turn off', or alienate audiences. Together, these two findings warrant further investigation in the context of how audiences interact with news. The pursuit of certain popular data visualisation formats, and the active avoidance of others, for fear of alienating news audiences, may yet have consequences for how we engage with and understand online news.

Future studies in this field may profitably interrogate the thoughts of noninteractive journalists on their interactives-producing peers (with particular emphasis on definitions of quality). A content analysis of output in this field may yield further insights into the values at play in news interactives, especially as they relate to the theories shared by professionals here. The rise of this non-journalistic form outside of the newsroom may yield valuable information too, especially in terms of how nonjournalists influence and inform the work of professional interactive journalists.

\section{References}


Allern, Sigurd. 2002. "Journalistic and commercial news values." Nordicom review 23: 137-152.

Bantz, Charles. 1997. "News Organizations: Conflict as a Crafted Cultural Norm". In Social Meanings of News: A Text Reader edited by Berkowitz, Dan. London: Sage. Bateman, Scott; Regan L. Mandryk; Carl Gutwin; Aaron Genest; David McDine and Christopher Brooks. 2010. "Useful Junk? The Effects of Visual Embellishment on Comprehension and Memorability of Charts", CHI 2010, April 10-15, 2010, Atlanta, Georgia, USA.

Boczkowski, Pablo. 2004. "The processes of adopting multimedia and interactivity in three online newsrooms". Journal of Communication, 54: 197-213.

Bogost, lan; Simon Ferrari and Bobby Schweizer. 2010. Newsgames : journalism at play. Massachusetts: The MIT Press.

Brinton, Willard C. 1914. Graphic Methods for Presenting Facts. New York, The Engineering magazine company.

Bruns, Axel. 2005. Gatewatching: Collaborative Online News Production. New York: Peter Lang.

BSI (British Standards Institution). 1992. British Standard 7581:1992 A Guide to the Presentation of Tables \& Graphs. London: British Standards Institute.

Chung, Deborah S. 2007. "Profits and perils: Online news producers' perceptions of interactivity and uses of interactive features". Convergence, 13(1): 43-61.

Deuze, Mark. 2008. "The Changing Context of News Work: liquid journalism and monitorial citizenship", International Journal of Communication, 2: 848-865.

Epstein, Edward J. 1973. News From Nowhere. New York: Random House.

Forlizzi, Jodi and Katja Battarbee. 2004. "Understanding Experience in Interactive Systems". Human-Computer Interaction Institute. Paper 46.

Franklin, Bob. 1997. Newszak and News Media. London: Arnold.

Galtung, Johan and Mari H. Ruge. 1965. "The Structure of Foreign News. The

Presentation of the Congo, Cuba and Cyprus Crises in Four Norwegian

Newspapers", Journal of Peace Research, 2: 64-91.

Gans, Herbert J. 1979. Deciding What's News A Study of CBS Evening News, NBC Nightly News, Newsweek and Time. New York: Pantheon Books.

Giardina, Marco and Pablo Medina. 2012. "Information graphics design challenges and workflow management". Paper presented at the International Conference on Communication, Media, Technology and Design, (ICCMTD), 09-11 May, 2012 in Istanbul, Turkey.

Golding, Peter and Phillip Elliott. 1979. Making the News. London: Longman.

Holmes, Nigel. 1984. Designer's Guide to Creating Charts and Diagrams. New York: Watson-Guptill Publications.

Gray, Jonathan, Lucy Chambers and Liliana Bounegru. 2012. The Data Journalism Handbook. London: O'Reilly.

ISO (International Organization for Standardization). 2009. International Standard 9241-210 Ergonomics of human system interaction-Part 210: Human-centred design for interactive systems. Geneva: International Organization for Standardization.

Kenney, Keith; Alexander Gorelik and Sam Mwangi. 1999. "Interactive Features of Online Newspapers", First Monday, 5(1).

Lang, Kurt and Gladys Lang. 1955. "The Inferential Structure of Political

Communications: A Study in Unwitting Bias”, Public Opinion Quarterly, 19: 168-183. Larsson, Anders Olof. 2012. "Interactivity on Swedish newspaper websites: what kind, how much and why?", Convergence, 18(2): 195-212. 
Lowrey, Wilson. 1999. "Routine news: The power of the organization in visual journalism", Visual Communication Quarterly, 6(2): 10-15.

Lowrey, Wilson. 2002a. "Word People vs. Picture People: Normative Differences and Strategies for Control Over Work Among Newsroom Subgroups", Mass

Communication and Society, 5(4): 411-432.

Lowrey, Wilson. 2002b. "The Influential Designer: Explaining Variability in Control Over News Presentation Work", Visual Communication Quarterly, 9(1): 4-13. Lowrey, Wilson. 2003. "Normative Conflict in the Newsroom: The Case of Digital Photo Manipulation”, Journal of Mass Media Ethics, 18(2), 123-142.

McMillan, Sally J. 2002. "A Four-part model of cyber-interactivity: Some Cyberplaces are more interactive than others", New Media and Society, 4(2): 271-291. Nichani, Maish and Venkat Rajamanickam. 2003. "Interactive Visual Explainers - A Simple Classification," eLearningPost, September 1:

http://www.elearningpost.com/articles/archives/interactive_visual_explainers_a_simpl e_classification/ (retrieved August 2013).

Prabu David. 1992. "Accuracy of Visual Perception of Quantitative Graphics: An Exploratory Study," Journalism Quarterly, Summer: 273-292.

Quandt, Thorsten. 2008. "(No) News on the world wide web?", Journalism Studies, 9(5): 717-738.

Rosenberry, Jack. 2005. "Few Papers use online techniques to improve public communication", Newspaper research journal, 26(4): 61-73.

Saffer, Dan, ed. 2010. Designing for Interaction Second Edition: Creating Innovative Applications and Devices. Berkley: New Riders.

Schlesinger, Philip. 1987. Putting 'reality' together: BBC news. London: Methuen.

Schroeder, Roland. 2004. "Interactive Info Graphics in Europe--added value to online mass media: a preliminary survey", Journalism Studies, 5(4): 563-570.

Schudson, Michael. 1997. "The Sociology of News Production". In Social Meanings of News: A Text Reader, edited by Berkowitz, Dan. New York: Sage.

Schultz, Ida. 2007. "The Journalistic gut feeling", Journalism Practice, 1(2): 190-207. Shultz, Tanjev. 1999. "Interactive options in online journalism: a content analysis of 100 US newspapers", Journal of Computer Mediated Communications, 5(1): http://jcmc.indiana.edu/vol5/issue1/schultz.html (retrieved August 2013). Tankard, James and Howard Ban. 1998. "Online Newspapers: Living up their Potential?". Paper presented at AEJMC conference Baltimore, MD., August. Tukey, John W. 1990. "Data-based graphics: visual display in the decades to come." Statistical Science, 5(3): 327-339.

Tufte, Edward. 1983. The Visual Display of Quantitative Information. Cheshire, Connecticut: Graphics Press.

Tunstall, Jeremy. 1971. Journalists at work. London: Constable.

\section{Author's contact details}

Email: $\quad$ murray.dick@brunel.ac.uk

Telephone: 01895265502

\section{Notes on author}


Murray Dick lectures on multi-platform journalism at Brunel University, London. Before joining Brunel, he was Information Officer at the Centre for Investigative Journalism, and before this he was a trainer in online research at the BBC (for five years). His research interests concern the sociologies of online journalism and data journalism. 